\title{
Mitral valve surgery for ischemic papillary muscle rupture: outcomes from the Japan cardiovascular surgery database
}

\author{
Tomoyuki Fujita $^{1}$ - Hiroyuki Yamamoto ${ }^{2,3}$. Junjiro Kobayashi ${ }^{1} \cdot$ Satsuki Fukushima ${ }^{1} \cdot$ Hiroaki Miyata $^{2,3}$. \\ Kizuku Yamashita ${ }^{1} \cdot$ Noboru Motomura $^{3}$
}

Received: 12 May 2020 / Accepted: 19 June 2020 / Published online: 25 June 2020

(c) The Author(s) 2020

\begin{abstract}
Background Ischemic papillary muscle rupture (PMR) is a catastrophic complication following acute myocardial infarction (AMI). We evaluated early outcomes of PMR by using data from the Japan Cardiovascular Surgery Database, a nationwide Japanese registry.

Methods We retrospectively analyzed data from 196 patients diagnosed with PMR following AMI in Japan between January 2014 and December 2017. Risk factors for operative mortality and severe complications following mitral valve surgery were analyzed.

Results The 30-day and hospital mortality rates were $20 \%$ and $26 \%$, respectively. Chronic hemodialysis, abrupt rupture after AMI, resuscitation before surgery, and preoperative venoarterial extracorporeal membrane oxygenation were associated with mortality. Mitral valve replacement was chosen mainly (90\%) for surgical correction of mitral regurgitation in these patients. There was no significant difference in short-term outcomes between mitral valve replacement versus mitral valve repair, despite non-matched characteristics in background between the treatment groups. Concomitant coronary artery bypass grafting had no impact on short-term outcomes.

Conclusions Information derived from the nationwide database of patients with AMI-associated PMR show that PMR is a rare condition in the modern era. However, PMR is a severe disease with a mortality rate as high as $26 \%$. The severity of the condition is associated with the risk for poor outcomes.
\end{abstract}

Keywords Acute myocardial infarction - Acute mitral regurgitation $\cdot$ Papillary muscle rupture $\cdot$ Mitral valve replacement . Mitral valve repair

Electronic supplementary material The online version of this article (https://doi.org/10.1007/s11748-020-01418-y) contains supplementary material, which is available to authorized users.

Tomoyuki Fujita

tfujita@ncvc.go.jp

1 Department of Cardiothoracic Surgery, National Cerebral and Cardiovascular Center, 6-1 Kishibeshimmachi, Suita, Osaka 564-8565, Japan

2 Department of Healthcare Quality Assessment, Graduate School of Medicine, The University of Tokyo, Tokyo, Japan

3 Japan Cardiovascular Surgery Database Organization, Tokyo, Japan

\section{Introduction}

Ischemic papillary muscle rupture (PMR), left ventricular rupture, and ventricular septal rupture are life-threatening mechanical complications following acute myocardial infarction (AMI) [1-6]. Ischemic PMR causes acute mitral regurgitation (MR) and results in cardiogenic shock, while acute elevation of left ventricular end-diastolic pressure produces pulmonary edema [1-6]. Vasopressors and inotropic agents are necessary to elevate systemic pressure, but these drugs in combination with increased preload can worsen pulmonary edema. Prompt surgical correction of MR is crucial. However, surgery in patients with AMI, especially emergency surgery, is always challenging. Mechanical support, such as intra-aortic balloon pumping (IABP) and venoarterial extracorporeal membrane oxygenation (VA-ECMO), is important to bridge to surgery for further 
hemodynamic support, although no data support a reduction in mortality rates with these therapies [7]. The percutaneous left ventricular assist device has recently been reported to be a useful bridge to surgery [8]. Mitral valve surgery to repair or replace the valve is the gold-standard treatment for this condition, as recommended in current guidelines $[9,10]$. However, reported mortality rates after mitral valve surgery are as high as 13-55\% [1-6]. Because of the rarity of ischemic PMR, few reports have been published on the subject. The risk factors for ischemic PMR remain unclear and the choice of mitral valve replacement (MVR) versus mitral valve repair (MVr) is controversial $[5,6,11]$. Therefore, we launched this study to explore early outcomes and risk factors for mitral valve surgery for PMR by using the Japan Cardiovascular Surgery Database (JCVSD).

\section{Methods}

\section{JCVSD}

The JCVSD is a national database used to assess surgical outcomes after cardiovascular procedures on a multicenter basis throughout Japan. The JCVSD captures clinical information from $99 \%$ of Japanese hospitals that perform cardiovascular surgery and comprised 591 hospitals in 2018 $[12,13]$. The JCVSD is now part of the National Clinical Database, which includes information concerning not only cardiovascular surgery but also thoracic surgery, general surgery, and neurosurgery. The data registration project was approved by the institutional review board at each participating hospital; review boards approved the collection of their data for use in the JCVSD. The method of data collection from the JCVSD has been previously described [12, 13]. More than 300 variables in the data collection form are nearly identical to those of the STS National Database. The content of the JCVSD is available online at https://www. jacvsd.umin.jp and can be verified with reference to that of the STS National Database (https://sts.org). The data manager of each participating hospital was responsible for forwarding patient data electronically to the central office. The rate of data entry was monitored annually in the central office to ensure comprehensive input of the data. The accuracy of submitted data was maintained through a data audit; administrative office members and investigators who had previously used the JCVSD for clinical studies randomly visited a participating hospital every month.

\section{Patients}

For the present study, use of data from 2014 to 2017 was approved by the Data Utilization Committee of the JCVSD. Following JCVSD approval in 2018, data analysis was undertaken. Ischemic PMR resulting from AMI was identified in 196 patients during the study period. Data collection, analysis, and reporting were approved by the National Cerebral and Cardiovascular Center Institutional Review Board on 17 October 2018 (IRB No.: M30-092).

\section{Study endpoints}

The primary endpoint of this study was 30-day mortality and operative mortality, defined as death within 30 days after mitral surgery and death during the primary hospitalization, respectively. Major morbidities during postoperative hospitalization included stroke, prolonged mechanical ventilation for $24 \mathrm{~h}$ or more, atrial fibrillation, newly required hemodialysis, including continuous veno-veno hemodialysis (or filtration), pneumonia, and deep sternal wound infection. We also compared the backgrounds and outcomes of patients who underwent MVR versus MVr.

\section{Definition of urgency of surgery}

Urgency of surgery was expressed as follows, according to the definition in the JCVSD website. Emergent: Patients requiring emergency operations in which there should be no delay in providing operative intervention. Salvage: Patients undergoing cardiopulmonary resuscitation en route to the operating room or during induction of anesthesia. Urgent: patients requiring urgent surgery within $24 \mathrm{~h}$ in order to minimize the chance of further clinical deterioration. Elective: none of the above.

\section{Statistical analysis}

Statistical analysis was performed with STATA 16 (STATA Corp., College Station, TX, USA). Continuous variables are presented as median (interquartile range). Categorical variables are presented as $n(\%)$. A 2-tailed $P<0.05$ was considered significant. Univariate comparisons of categorical and continuous variables were made with Fisher's exact test and Wilcoxon rank-sum test, respectively. Univariate logistic regression analysis was performed to identify risk factors for operative mortality and/or stroke. Risk factors included age category (10-year age groups), sex, preoperative chronic dialysis, ST-elevated or non-elevated myocardial infarction, duration from onset to surgery, history of percutaneous coronary intervention (PCI), history of resuscitation, preoperative VA-ECMO, MVR or MVr, and concomitant coronary artery bypass grafting (CABG). 


\section{Results}

Patient characteristics are shown in Table 1. The median patient age was 74 years; $26 \%$ of the patients were older than 80 years. Thirty-nine percent of patients were women. The median body mass index was $22 \mathrm{~kg} / \mathrm{m}^{2}$; only $5 \%$ of patients had a body mass index above $30 \mathrm{~kg} / \mathrm{m}^{2}$. Hypertension and dyslipidemia were found in 55\% and $31 \%$ of patients, respectively. Diabetes mellitus was found in $25 \%$ of patients. Renal dysfunction [estimated glomerular filtration rate (eGFR) less than $60 \mathrm{~mL} / \mathrm{min} / 1.73 \mathrm{~m}^{2}$ ] was present in $79 \%$ of patients; $2.6 \%$ of these were receiving dialysis. In terms of type of AMI, $69 \%$ of patients were diagnosed with ST-elevated myocardial infarction and $19 \%$ were diagnosed with non-ST-elevated myocardial infarction. One-third of the patients developed PMR within $24 \mathrm{~h}$ after AMI. As for the severity of disease, $90 \%$ of patients were NYHA class 3 or $4,70 \%$ had cardiogenic shock, $32 \%$ required VA-ECMO, and $80 \%$ required IABP support. Furthermore, $12 \%$ of patients required resuscitation before surgery. Coronary angiogram was performed in $89 \%$ of patients and showed significant stenosis $(75 \%$ or more) in the left anterior descending coronary artery (43\%), circumflex artery (52\%), and right coronary artery (47\%). The remaining patients underwent surgery without coronary angiogram.

A summary of interventions and surgeries is shown in Table 2. Emergency mitral valve surgery was performed in $57 \%$ of patients; only $13 \%$ of patients underwent elective surgery. PCI and concomitant CABG were performed in $47 \%$ and $31 \%$ of patients, respectively. Nearly $90 \%$ of patients underwent MVR and only 10\% underwent MVr.

The 30-day and hospital mortality rates were $20 \%$ and $26 \%$, respectively (Table 3 ). The incidence of the composite outcome of mortality and stroke was $32 \%$. Prolonged ventilation was needed in $28 \%$ of patients and new-onset hemodialysis was needed in $18 \%$. The median postoperative stay was 28 days. During hospitalization, $11 \%$ of patients developed pneumonia and $3 \%$ developed deep sternal infection.

To analyze the risk factors for 30-day and hospital mortality and for the composite outcome of mortality and stroke, several background, and surgical variables were selected (Table 4). The odds ratio increased with age, although the difference was not statistically significant. Chronic hemodialysis, resuscitation within $1 \mathrm{~h}$ before surgery, and preoperative VA-ECMO were risk factors for 30-day mortality, hospital mortality, and the composite outcome of mortality and stroke. An interval longer than $24 \mathrm{~h}$ between AMI and PMR was protective for mortality. There were no significant differences in short-term outcomes between patients who underwent concomitant $\mathrm{CABG}$ versus those who did not or between those who underwent MVR versus MVr.
Table 1 Baseline characteristics of patients with papillary muscle rupture

\begin{tabular}{|c|c|}
\hline Variables & Total \\
\hline Number & 196 \\
\hline age & $74(67-80)$ \\
\hline \multicolumn{2}{|l|}{ Age category } \\
\hline-59 & $14(7.1 \%)$ \\
\hline $60-69$ & $51(26.0 \%)$ \\
\hline $70-79$ & $80(40.8 \%)$ \\
\hline $80-$ & $51(26.0 \%)$ \\
\hline Sex (male) & $119(60.7 \%)$ \\
\hline BMI (median) & $22.25(20.5-24.55)$ \\
\hline BMI (> 30) & $10(5.1 \%)$ \\
\hline Hypertension & $107(54.6 \%)$ \\
\hline Dyslipidemia & $60(30.6 \%)$ \\
\hline Diabetes mellitus & $48(24.5 \%)$ \\
\hline Respiratory disease & $25(12.8 \%)$ \\
\hline Peripheral vascular disease & $4(2.0 \%)$ \\
\hline Cerebral infarction & $19(9.7 \%)$ \\
\hline eGFR & $40.1(28.1-54.9)$ \\
\hline eGFR $(<60)$ & $153(78.9 \%)$ \\
\hline Chronic hemodialysis & $5(2.6 \%)$ \\
\hline Previous cardiac surgery & $3(1.5 \%)$ \\
\hline \multicolumn{2}{|l|}{ Type of MI } \\
\hline STEMI & $136(69.4 \%)$ \\
\hline NSTEMI & $38(19.4 \%)$ \\
\hline Unknown & $22(11.2 \%)$ \\
\hline \multicolumn{2}{|l|}{ Interval between MI to PMR } \\
\hline$\sim 24 \mathrm{~h}$ & $67(34.2 \%)$ \\
\hline $24 \mathrm{~h} \sim$ & $116(59.2 \%)$ \\
\hline Unknown & $13(6.6 \%)$ \\
\hline LVEF $<30 \%$ & $20(10.2 \%)$ \\
\hline NYHA class3or 4 & $177(90.3 \%)$ \\
\hline Cardiogenic shock & $140(71.4 \%)$ \\
\hline Resuscitation within $1 \mathrm{~h}$ before surgery & $23(11.7 \%)$ \\
\hline Preoperative VA-ECMO & $63(32.1 \%)$ \\
\hline Preoperative IABP & $159(81.1 \%)$ \\
\hline Coronary angiogram performed & $174(88.8 \%)$ \\
\hline \multicolumn{2}{|l|}{ Coronary lesion } \\
\hline LMT & $5(2.9 \%)$ \\
\hline LAD & $75(43.1 \%)$ \\
\hline $\mathrm{LCx}$ & $90(51.7 \%)$ \\
\hline RCA & $82(47.1 \%)$ \\
\hline
\end{tabular}

$B M I$ body mass index, $e G F R$ estimated glomerular filtration rate, $I A B P$ intra-aortic balloon pump, $L A D$ left anterior descending artery, $L C x$ left circumflex artery, $L M T$ left main trunk, $L V E F$ left ventricular ejection fraction, MI myocardial infarction, NSTEMI non-STelevation myocardial infarction, NYHA New York Heart Association, $P M R$ papillary muscle rupture, $R C A$ right coronary artery, STEMI ST-elevation myocardial infarction, $V A-E C M O$ venoarterial extracorporeal membrane oxygenation 
Table 2 Characteristics of Surgeries and Interventions

\begin{tabular}{ll}
\hline Variables & Total \\
\hline Number & 196 \\
Urgency of surgery & \\
Emergent & $112(57.1 \%)$ \\
Urgent & $49(25.0 \%)$ \\
Salvage & $9(4.6 \%)$ \\
Elective & $26(13.3 \%)$ \\
PCI performed within this episode & $93(47.4 \%)$ \\
Concomitant CABG & $60(30.6 \%)$ \\
MVR & $176(89.8 \%)$ \\
Procedure time (min) & $289(240.5-366)$ \\
Cardiopulmonary bypass time (min) & $156(123-204)$ \\
Cardiac arrest time (min) & $92(75-121)$ \\
\hline
\end{tabular}

$C A B G$ coronary artery bypass grafting, $M V R$ mitral valve replacement, $P C I$ percutaneous coronary intervention

Table 3 Outcomes

\begin{tabular}{ll}
\hline Variables & Total \\
\hline Number & 196 \\
30-day mortality & $40(20.4 \%)$ \\
Operative mortality & $50(25.5 \%)$ \\
Stroke & $16(8.2 \%)$ \\
Composite of death or stroke & $62(31.6 \%)$ \\
Prolonged ventilation $(>24 \mathrm{hrs})$ & $54(27.6 \%)$ \\
Atrial fibrillation & $38(19.4 \%)$ \\
Newly dialysis & $35(17.9 \%)$ \\
Pneumonia & $22(11.2 \%)$ \\
Deep sternal infection & $6(3.1 \%)$ \\
Postoperative stay & $28(17-57)$ \\
\hline
\end{tabular}

Differences in backgrounds of patients who underwent MVR versus $M V r$ were evaluated. The MVr group was younger and had higher eGFR than the MVR group and included fewer shock patients (Table 5). MVr was less often selected in emergency situations. The operation time, cardiopulmonary bypass time, and cardiac arrest time were similar in both groups, and concomitant CABG was performed equally in both groups. Surgical outcomes, including mortality and stroke, were similar in both groups.

\section{Discussion}

PMR is a very rare condition, especially in the modern era. The APEX-AMI trial, which recruited patients with ST-elevation myocardial infarction from 17 countries and 296 sites from 2004 to 2006, found a $0.26 \%$ incidence of PMR following AMI; more recently that rate was $0.029 \%$, according to data derived from the National Inpatient Sample in the USA from 2005 to 2014 [3, 4]. Our study included data from 196 patients in the JCVSD, which captured clinical information from $99 \%$ of Japanese hospitals that performed cardiovascular surgery from 2014 to 2017 (4 years). According to data from the Japanese Circulation Society (https://www.j-circ. or.jp), which captures clinical information given from the $62 \%$ of the hospitals which have cardiology departments, the estimated number of AMI patients was 288,922 during the same period in Japan. Therefore, the incidence of PMR following AMI in Japan is also very low. Compared with data from past decades, the modern approach to AMI, which includes early reperfusion with thrombolysis or PCI, has successfully decreased the incidence of PMR $[4,14]$.

Rupture of the posteromedial papillary muscle occurs 6-12 times more frequently than rupture of the anterolateral papillary muscle. [1] Whereas the anterolateral papillary muscle has a dual blood supply from the left anterior descending and circumflex arteries, the posteromedial papillary muscle has a single blood supply from the posterior descending artery $[15,16]$. Complete rupture of the papillary muscles results in catastrophic hemodynamics, as revealed by transesophageal echocardiography with colorflow Doppler (Fig. 1a). Surgical findings include a necrotic left ventricular wall and ruptured papillary muscle (Fig. 1b, $\mathrm{c}$ and supplementary file of surgical video). Pathological examination of the papillary muscle shows coagulation necrosis of myocytes (Fig. 1d). These findings indicate that PMR is related to the extent of AMI.

Although PMR is usually diagnosed between 2 to 7 days after AMI, the reported median time to PMR is $13 \mathrm{~h}$ [17]. In the present study, $34 \%$ of patients presented within $24 \mathrm{~h}$ after AMI. At presentation, more than $90 \%$ of patients were in severe heart failure (NYHA class 3 or higher) and more than $70 \%$ were in cardiogenic shock. Prompt mechanical support, such as IABP ( $81 \%)$ and VA-ECMO (32\%), was used as a bridge to surgery. IABP decreases afterload, resulting in less MR and more forward flow from the left ventricle [18]. VA-ECMO, which stabilizes hemodynamics and improves oxygenation, is ideal mechanical support, but can sometimes worsen pulmonary congestion by elevating left ventricular end-diastolic pressure [19]. The findings in the present study that the use of VA-ECMO, the interval between AMI and PMR, and the need for preoperative resuscitation were significant risk factors for mortality suggest that the severity of disease influences the outcomes.

Coronary revascularization is a key to improving shortterm and long-term survival rates. Concomitant CABG improved short- and long-term outcomes in recent studies, although there was no significant difference in mortality rates between patients with versus without $\mathrm{CABG}$ in this study [5, 6]. Only $31 \%$ of patients in the present study underwent concomitant $\mathrm{CABG}$, whereas $47 \%$ underwent 
Table 4 Predictors of 30-day mortality, hospital mortality, and composite outcome of mortality and stroke: univariate analysis

\begin{tabular}{|c|c|c|c|c|c|c|}
\hline \multirow[t]{2}{*}{ Variables } & \multicolumn{2}{|l|}{ 30-day mortality } & \multicolumn{2}{|l|}{ Operative mortality } & \multicolumn{2}{|c|}{ Operative mortality or storke } \\
\hline & Odds ratio $(95 \% \mathrm{CI})$ & $p$ value & Odds ratio $(95 \% \mathrm{CI})$ & $p$ value & Odds ratio $(95 \% \mathrm{CI})$ & $p$ value \\
\hline \multicolumn{7}{|l|}{ Age category } \\
\hline-59 & $1.00(1.00-1.00)$ & & $1.00(1.00-1.00)$ & & $1.00(1.00-1.00)$ & \\
\hline $60-69$ & $1.73(0.19-15.72)$ & 0.62 & $1.12(0.21-5.97)$ & 0.90 & $2.27(0.45-11.45)$ & 0.32 \\
\hline $70-79$ & $3.77(0.46-30.84)$ & 0.22 & $2.42(0.50-11.68)$ & 0.27 & $3.23(0.67-15.47)$ & 0.14 \\
\hline $80-$ & $5.42(0.65-45.18)$ & 0.12 & $3.00(0.60-14.95)$ & 0.18 & $3.27(0.66-16.26)$ & 0.15 \\
\hline Sex (male) & $0.58(0.29-1.16)$ & 0.12 & $0.55(0.29-1.06)$ & 0.07 & $0.70(0.38-1.29)$ & 0.25 \\
\hline Chronic hemodialysis & $6.24(1.01-38.72)$ & 0.05 & $12.61(1.37-115.66)$ & 0.03 & $9.17(1.00-83.86)$ & 0.05 \\
\hline STEMI & $1.02(0.42-2.45)$ & 0.97 & $0.97(0.43-2.20)$ & 0.94 & $1.00(0.33-3.12)$ & 0.98 \\
\hline Interval between MI to PMR (>24hrs) & $0.30(0.14-0.64)$ & $<0.01$ & $0.39(0.20-0.78)$ & 0.01 & $0.60(0.32-1.14)$ & 0.12 \\
\hline Resuscitation within $1 \mathrm{~h}$ before surgery & $3.67(1.47-9.14)$ & 0.01 & $2.56(1.04-6.27)$ & 0.04 & $2.68(1.11-6.48)$ & 0.03 \\
\hline Preoperative VA-ECMO & $6.92(3.24-14.79)$ & $<0.01$ & $5.14(2.59-10.20)$ & $<0.01$ & $6.15(3.16-11.94)$ & $<0.01$ \\
\hline Cocomitant CABG & $0.83(0.38-1.79)$ & 0.63 & $0.85(0.42-1.72)$ & 0.64 & $0.90(0.46-1.73)$ & 0.74 \\
\hline MVR & $2.48(0.55-11.16)$ & 0.24 & $1.42(0.45-4.45)$ & 0.55 & $1.09(0.40-2.98)$ & 0.87 \\
\hline
\end{tabular}

$C A B G$ coronary artery bypass grafting, $M I$ myocardial infarction, $P M R$ papillary muscle rupture, STEMI ST-elevation myocardial infarction, $V A$ $E C M O$ venoarterial extracorporeal membrane oxygenation

perioperative PCI, because PCI is generally performed before surgery in current practice. The increasing use of prompt reperfusion therapies for AMI as a class I treatment appears to reduce the necessity of concomitant CABG [4]. Preoperative PCI may contribute to reduce cardiopulmonary bypass time and operation time. The hybrid therapy of PCI and surgery for PMR may be the standard, in the era of primary PCI.

Whereas MVr is reportedly safe and effective, Russo et al. found no significant difference in 5-year survival between MVR and MVr after PMR [5, 11]. In the present study, short-term outcomes were the same for MVR and MVr after PMR. Patients who underwent MVr had lower urgency and required less mechanical support than those who underwent MVR. MVr was performed for only $10 \%$ of patients in this study. The procedure time, cardiopulmonary bypass time, and cardiac arrest time were the same in both groups. Long-term follow-up is necessary to find the difference between MVr and MVR for PMR. Concomitant CABG should be considered if catheter revascularization has not been performed.

Recently, analysis of the outcomes of mitral valve surgery for PMR from STS database was published [20]. They analyzed 1342 patients during 8 years in the USA. Similar to our results, $52 \%$ of patients required emergent or salvage operation ( $61.7 \%$ in our data), but only $3.1 \%$ were connected ECMO $(32.1 \%$ in our data). The operative mortality was $20 \%(25.5 \%$ in our data) and stroke rate was $5.2 \%(8.2 \%$ in our data). As showing that preoperative VA-ECMO was a risk factor for operative mortality, management to escape from VA-ECMO may be required. Prior PCI was done in $44.5 \%$ and concomitant CABG was done in $59.3 \%$ of patients in their study, as those were done in $47.4 \%$ and $30.6 \%$ in our study. Regarding selection of mitral valve surgery in their study, $80 \%$ of patients underwent MVR instead of $\mathrm{MVr}$ and had severer background such as cardiogenic shock (MVR vs MVr; $65.9 \%$ vs 19.3\%), ST-Elevation MI (20.4\% vs $1.9 \%)$, requiring emergency operation or salvage (60.9\% vs $17.1 \%)$. Although operative mortality was different between MVR and MVr, MVr has been reserved only for select cases in less decompensated patients, who may have potentially partial PMR. Despite some differences were seen between their study in the USA and our study, complexity of managing PMR was exposed similarly.

There are several important study limitations resulting from the nature of the JCVSD. Because post-hospitalization (longitudinal) data were not available, there are no longterm outcome data. Therefore, long-term survival could not be evaluated. Neither the details of PCI (such as timing and lesions treated) nor sites of AMI (anterior, posterior, or inferior) were available in registry data. It is difficult to precisely assess the relationships between comorbidities and in-hospital events. In addition, the timing and sequence of certain clinical events during hospitalization cannot be assessed with accuracy. The JCVSD does not contain details of imaging, laboratory results, or hemodynamic data.

In conclusion, data on patients with AMI-associated PMR collected from the nationwide database show that PMR is a rare condition in the modern era. However, PMR is a severe disease with a mortality rate as high as $26 \%$ 
Table 5 Comparison of

characteristics and outcomes of patients with MVr versus MVR

\begin{tabular}{|c|c|c|c|}
\hline Variables & $\mathrm{MVr}$ & MVR & p-value \\
\hline Number & 20 & 176 & \\
\hline \multicolumn{4}{|l|}{ Patient background } \\
\hline Age & $66.5(62-76)$ & $75(68-81)$ & 0.003 \\
\hline Sex (male) & $17(85.0 \%)$ & $102(58.0 \%)$ & 0.027 \\
\hline eGFR & 49.65 (41.95-61.8) & $38.85(26.4-54)$ & 0.020 \\
\hline \multicolumn{4}{|l|}{ Interval between $\mathrm{MI}$ to PMR } \\
\hline$\sim 24 \mathrm{~h}$ & $1(5.0 \%)$ & $66(37.5 \%)$ & 0.004 \\
\hline $24 \mathrm{~h} \sim$ & $18(90.0 \%)$ & $98(55.7 \%)$ & \\
\hline Unknown & $1(5.0 \%)$ & $12(6.8 \%)$ & \\
\hline Cardiogenic shock & $7(35.0 \%)$ & $133(75.6 \%)$ & $<0.001$ \\
\hline Resuscitation within $1 \mathrm{~h}$ before surgery & $0(0.0 \%)$ & $23(13.1 \%)$ & 0.14 \\
\hline Preoperative VA-ECMO & $4(20.0 \%)$ & $59(33.5 \%)$ & 0.31 \\
\hline Preoperative IABP & $11(55.0 \%)$ & $148(84.1 \%)$ & 0.004 \\
\hline \multicolumn{4}{|l|}{ Intervention and surgery } \\
\hline \multicolumn{4}{|l|}{ Urgency of surgery } \\
\hline Emergent & $3(15.0 \%)$ & $109(61.9 \%)$ & $<0.001$ \\
\hline Urgent & $8(40.0 \%)$ & $41(23.3 \%)$ & \\
\hline Salvage & $0(0.0 \%)$ & $9(5.1 \%)$ & \\
\hline Elective & $9(45.0 \%)$ & $17(9.7 \%)$ & \\
\hline Cocomitant CABG & $6(30.0 \%)$ & $54(30.7 \%)$ & 1.00 \\
\hline Procedure time (min) & $286(238.5-386)$ & $290(240.5-365.5)$ & 0.95 \\
\hline Cardiopulmonary bypass time (min) & 166.5 (129-209.5) & $153(122-204)$ & 0.30 \\
\hline Cardiac arrest time (min) & $105(85.5-144.5)$ & $92(75-120)$ & 0.12 \\
\hline \multicolumn{4}{|l|}{ Outcomes } \\
\hline 30-day mortality & $2(10.0 \%)$ & $38(21.6 \%)$ & 0.38 \\
\hline Hospital mortality & $4(20.0 \%)$ & $46(26.1 \%)$ & 0.79 \\
\hline Stroke & $2(10.0 \%)$ & $14(8.0 \%)$ & 0.67 \\
\hline Composite of death or stroke & $6(30.0 \%)$ & $56(31.8 \%)$ & 1.00 \\
\hline Prolonged ventilation (> 24hrs) & $4(20.0 \%)$ & $50(28.4 \%)$ & 0.84 \\
\hline Atrial fibrillation & $3(15.0 \%)$ & $35(19.9 \%)$ & 0.77 \\
\hline Newly dialysis & $4(20.0 \%)$ & $31(17.6 \%)$ & 0.76 \\
\hline Pneumonia & $2(10.0 \%)$ & $20(11.4 \%)$ & 1.00 \\
\hline Deep sternal infection & $0(0.0 \%)$ & $6(3.4 \%)$ & 1.00 \\
\hline Postoperative hospital stay & $25(19-52)$ & $28.5(16.5-57)$ & 0.84 \\
\hline
\end{tabular}

$C A B G$ coronary artery bypass grafting, $e G F R$ estimated glomerular filtration rate, IABP intra-aortic balloon pump, $M I$ myocardial infarction, $M V r$ mitral valve repair, $M V R$ mitral valve replacement, $P M R$ papillary muscle rupture, $V A-E C M O$ venoarterial extracorporeal membrane oxygenation

and associated morbidities, such as kidney injury, pneumonia, and stroke. The severity of the condition, indicated by rapid progression of PMR or cardiogenic shock requiring resuscitation and/or VA-ECMO, is a risk factor for survival. Although revascularization is a key to treatment, aggressive PCI masks the benefit of concomitant CABG in modern Japan. MVR is more selected than MVr for the surgical correction of MR. 


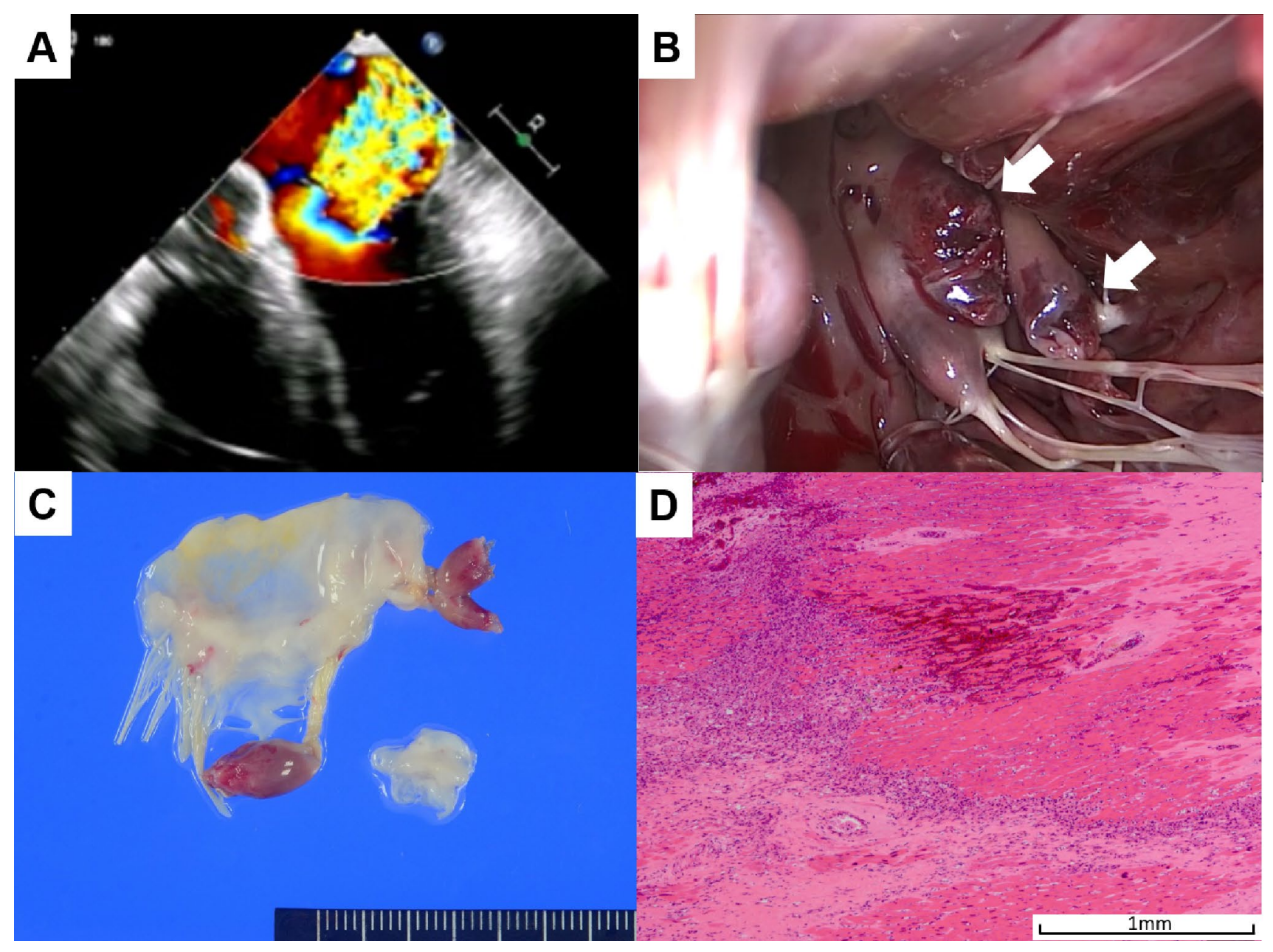

Fig. 1 a Transesophageal color-flow Doppler image demonstrating severe mitral regurgitation resulting from flail papillary muscle. b Intraoperative photograph showing necrotic left ventricular wall and ruptured papillary muscle (white arrows). c Surgical specimen

Acknowledgement We would like to thank Professor Sinichi Takamoto for establishing JCVSD as a chairman, and the data managers at the JCVSD participating institutes for their considerable efforts in data registration. We also thank Rebecca Tollefson, DVM, from Edanz Group (https://en-author-services.edanzgroup.com/) for editing a draft of this manuscript.

Funding This work was supported by The Japanese Society for Cardiovascular Surgery Clinical Investigation Project Award in 2017.

\section{Compliance with ethical standards}

Conflict of interest HY and HM are affiliated with the Department of Healthcare Quality Assessment at The University of Tokyo, which is a social collaboration department supported by Grants from National Clinical Database, Johnson \& Johnson K.K., and Nipro Co. TF, KY, $\mathrm{JK}$, and SF have no conflicts of interest.

IRB information This study was approved by the National Cerebral and Cardiovascular Center Institutional Review Board (Reference Number: M30-092). of anterior mitral leaflet and ruptured papillary muscle. d Pathological examination (HE stain) of papillary muscle showing coagulation necrosis of myocytes

Open Access This article is licensed under a Creative Commons Attribution 4.0 International License, which permits use, sharing, adaptation, distribution and reproduction in any medium or format, as long as you give appropriate credit to the original author(s) and the source, provide a link to the Creative Commons licence, and indicate if changes were made. The images or other third party material in this article are included in the article's Creative Commons licence, unless indicated otherwise in a credit line to the material. If material is not included in the article's Creative Commons licence and your intended use is not permitted by statutory regulation or exceeds the permitted use, you will need to obtain permission directly from the copyright holder. To view a copy of this licence, visit http://creativecommons.org/licenses/by/4.0/.

\section{References}

1. Thompson CR, Buller CE, Sleeper LA, Antonelli TA, Webb JG, Jaber WA, et al. Cardiogenic shock due to acute severe mitral regurgitation complicating acute myocardial infarction: a report from the SHOCK trial registry. J Am Coll Cardiol. 2000;36:1104-9. 
2. Alajaji WA, Akl EA, Farha A, Jaber WA, AlJaroudi WA. Surgical versus medical management of patients with acute ischemic mitral regurgitation: a systematic review. BMC Res Notes. 2015;8:712. https://doi.org/10.1186/s13104-015-1704-9.

3. Bhardwaj B, Sidhu G, Balla S, Kumar V, Kumar A, Aggarwal K, et al. Outcomes and hospital utilization in patients with papillary muscle rupture associated with acute myocardial infarction. Am J Cardiol. 2020;125:1020-5.

4. French JK, Hellkamp AS, Armstrong PW, Cohen E, Kleiman NS, O'Connor CM, et al. Mechanical complications after percutaneous coronary intervention in ST-elevation myocardial infarction (from APEX-AMI). Am J Cardiol. 2010;105:59-63.

5. Russo A, Suri RM, Grigioni F, Roger VL, Oh JK, Mahoney DW, et al. Clinical outcome after surgical correction of mitral regurgitation due to papillary muscle rupture. Circulation. 2008;118:1528-34.

6. Kutty RS, Jones N, Moorjani N. Mechanical complications of acute myocardial infarction. Cardiol Clin. 2013;31:519-31.

7. Sjauw KD, Engstrom AE, Vis MM, van der Schaaf RJ, Baan $\mathrm{J} \mathrm{Jr}$, Koch KT, et al. A systematic review and meta-analysis of intra-aortic balloon pump therapy in ST-elevation myocardial infarction: should we change the guidelines? Eur Heart J. 2009;30:459-68.

8. Jalil B, El-Kersh K, Frizzell J, Ahmed S. Impella percutaneous left ventricular assist device for severe acute ischaemic mitral regurgitation as a bridge to surgery. BMJ Case Rep. 2017. https://doi. org/10.1136/bcr-2017-219749.

9. Nishimura RA, Otto CM, Bonow RO, Carabello BA, Erwin JP 3rd, Guyton RA, et al. 2014 AHA/ACC guideline for the management of patients with valvular heart disease: executive summary: a report of the American College of Cardiology/American Heart Association Task Force on Practice Guidelines. Circulation. 2014;129:2440-922.

10. Baumgartner H, Falk V, Bax JJ, De Bonis M, Hamm C, Holm PJ, et al. 2017 ESC/EACTS guidelines for the management of valvular heart disease. Eur Heart J. 2017;38:2739-91.

11. Bouma W, Wijdh-den Hamer IJ, Klinkenberg TJ, Kuijpers M, Bijleveld A, van der Horst IC, et al. Mitral valve repair for postmyocardial infarction papillary muscle rupture. Eur J Cardiothorac Surg. 2013;44:1063-9.

12. Daimon M, Miyata H, Motomura N, Okita Y, Takamoto S, Kanki $\mathrm{S}$, et al. Outcomes of thoracic aortic surgery in patients with coronary artery disease -Based on the Japan Adult Cardiovascular Surgery Database. Circ J. 2019;83:978-84.

13. Tokuda Y, Yamamoto H, Miyata H, Usui A, Motomura N, Japan Cardiovascular Surgery Database Organization. Contemporary outcomes of surgical aortic valve replacement in Japan. Circ J. 2020;84:277-82.

14. Badheka AO, Patel NJ, Grover P, Singh V, Patel N, Arora S, et al. Impact of annual operator and institutional volume on percutaneous coronary intervention outcomes: a 5-year United States experience (2005-2009). Circulation. 2014;130:1392-406.

15. Barbour DJ, Roberts WC. Rupture of a left ventricular papillary muscle during acute myocardial infarction: analysis of 22 necropsy patients. J Am Coll Cardiol. 1986;8:558-65.

16. Voci P, Bilotta F, Caretta Q, Mercanti C, Marino B. Papillary muscle perfusion pattern: a hypothesis for ischemic papillary muscle dysfunction. Circulation. 1995;91:1714-8.

17. Menon V, Webb JG, Hillis LD, Sleeper LA, Abboud R, Dzavik $\mathrm{V}$, et al. Outcome and profile of ventricular septal rupture with cardiogenic shock after myocardial infarction: a report from the SHOCK Trial Registry. J Am Coll Cardiol. 2000;36(Suppl A):1110-6.

18. Ryan TJ, Antman EM, Brooks NH, Califf RM, Hillis LD, Hiratzka LF, et al. 1999 update: ACC/AHA guidelines for the management of patients with acute myocardial infarction. A report of the American College of Cardiology/American Heart Association Task Force on Practice Guidelines (committee on management of acute myocardial infarction). J Am Coll Cardiol. 1999;34:890-911.

19. Obadia B, Théron A, Gariboldi V, Collart F. Extracorporeal membrane oxygenation as a bridge to surgery for ischemic papillary muscle rupture. J Thorac Cardiovasc Surg. 2014;147:e82-e8484.

20. Kilic A, Sultan I, Chu D, Wang Y, Gleason TG. Mitral valve surgery for papillary muscle rupture: outcomes in 1342 patients from the STS database. Ann Thorac Surg. 2020;S00034975(20):30694-9. https://doi.org/10.1016/j.athor acsur .2020.03.097.

Publisher's Note Springer Nature remains neutral with regard to jurisdictional claims in published maps and institutional affiliations. 